\title{
The impact of forced mergers and acquisitions on banks' total factor productivity: empirical evidence from Malaysia
}

\begin{abstract}
In the present paper, we employ alternative techniques to examine the impact of mergers and acquisitions on the total factor productivity of Malaysian banks. These alternative techniques extend from the use of non-parametric ófontierôoriented Malmquist productivity index (MPI) and central tendency ordinary least square (OLS) and fixed effects (FE) panel regression methods. We find that Malaysian banks have exhibited a higher mean total factor productivity level during the post-merger period. The results from the multivariate regression analysis suggest that income diversification and operating expenses are positively and significantly related to Malaysian banksô total factor productivity, while credit risk and inflation exhibit a negative relationship. The empirical findings indicate that the acquiring banks have been relatively more productive compared to the target banks and banks in the control group.
\end{abstract}

Keyword: Mergers and acquisitions; Malmquist productivity index; Multivariate regressions; Malaysia 